\title{
Peer helpers' construction of their role in an open distance-learning institution
}

\author{
S E Mabizela, MA Psychology \\ Centre for Health Science Education, University of the Witwatersrand, Johannesburg, South Africa
}

Corresponding author: S E Mabizela (sfiso.mabizela@wits.ac.za)

\begin{abstract}
Background. The University of South Africa (UNISA) offers educational programmes through distance learning. Because of the institution's elasticity and character, the UNISA Peer Help Volunteer Programme was developed to extend support to students, to disseminate educational information to schools and the surrounding communities and to engender personal and professional growth of peer helpers.

Objectives. To explore the modalities used by peer helpers to construct their roles as sources of support at the university.

Methods. A qualitative approach was used, underpinned by the social constructionist paradigm as an epistemological position. The sample consisted of 6 peer helpers. Data were analysed using thematic analysis.

Results. Three themes were identified, i.e. peers as distributors of information, the peer-help role as an opportunity to integrate theory and practice and the peer-help role as a personal eye-opener.

Conclusion. The findings showed that peer helpers understand the challenges faced by other students and the institutional character of the university and were able to use their experiences in conjunction with available resources to assist their fellow students and to reach out to disseminate educational information to communities.
\end{abstract}

Afr J Health Professions Educ 2018;10(3):166-170. DOI:10.7196/AJHPE.2018.v10i3.1029

The University of South Africa (UNISA) is an open distance-learning (ODL) institution, and most undergraduate programmes are offered through the distance-learning model. Because of UNISA's elasticity and institutional character, the UNISA Peer Help Volunteer Programme (UPHVP) was developed to expand the range of support to students, to render careerguidance services to schools and the surrounding communities and to create a conducive environment for peer helpers to generate personal and professional growth (Van Schoor and Mill - unpublished information, 1998). UNISA peer helpers are senior students majoring in psychology, who volunteered to join the peer-help programme to assist other students. In brief, peer helpers are trained to expand the network of support for UNISA's student population, to broaden the range of guidance services to the school and the community and to empower peer helpers to acquire valuable personal and employment skills and abilities (Van Schoor and Mill - unpublished information, 1998).

The UPHVP was initiated in 1996 at UNISA's Pretoria main campus and the Cape Town regional campus. Its success has led to its expansion to other regional campuses across the country. UNISA's institutional character encapsulates, among other matters, reasonable, lower study fees and flexible tuition methods that offer opportunities for students to study and work simultaneously. As a result, UNISA is a melting pot where diverse students from various socioeconomic statuses, age groups and areas pursue different careers. In the realm of that context, Subotzky and Prinsloo ${ }^{[1]}$ argued that most UNISA students are not orientated to the challenges of higher learning, which is attributable to the lasting legacy of apartheid and substandard schooling systems. Moreover, the majority of UNISA students study in isolation, some study part-time while employed full-time, and some are full-time students who are underprepared for distance education (Van Schoor and Mill - unpublished information, 1998).
The UPHVP falls under the Directorate for Counselling and Career Development (DCCD), which seeks to support prospective and registered students before, during and after registration. The UPHVP was established for the realisation of three specific goals, i.e. to expand the network of support for UNISA's student population, to widen the range of guidance services to schools and the community and to empower peer helpers to develop critical personal and employability skills and abilities (Van Schoor and Mill - unpublished information, 1998). These goals were and are being achieved through the utilisation of peer helpers who act as first contacts in their individual capacity to assist others (Mabizela - unpublished information, 2015). The peer helpers are volunteer, senior students majoring in psychology, who are committed to helping others. ${ }^{[2]}$ The core responsibilities of peer helpers were mapped out (Van Schoor and Mill - unpublished information, 1998).

\section{UNISA peer-help roles and responsibilities}

- Make the student population and the university environment aware of the availability of the UPHVP and promote the role of peer help in general.

- Assist in the day-to-day running of the Peer Help Office by ensuring that it is part of the attendant roster for service delivery.

- Provide a service to fellow students by staffing the Peer Help Office, answering telephones and replying to internet requests for help.

- Establish positive helping relationships with all fellow students by attending to them, listening empathically and responding skilfully during interviews.

- Actively participate in the expansion of their individual knowledge bases about academic, personal and career matters by regularly attending supervision sessions and completing assignments aimed at empowering the peer-help volunteers. 
- Work effectively with fellow students by providing information about careers, subjects and study possibilities.

- At all times be aware of administrative procedures and deadlines, including registration dates, cancellations and examination procedures.

- Be familiar with the location of academic and administrative departments and support structures on the campus to promote effective referrals.

- At all times be aware of their personal limitations and recognised boundaries of individual competencies, training and experience. The peer helpers should be sensitised to be aware of the risks of transgressing boundaries.

- Understand what an emergency entails and be familiar with the referral procedures to expedite these to professional counsellors.

- Manage voluntary activities and maintain records of all contacts (Van Schoor and Mill - unpublished information, 1998).

The tendency of students to turn to their fellow students for help during difficult circumstances is a well-noted phenomenon in the literature of peer-help programmes. ${ }^{[3-5]}$ Fellow students do not only play a vital role in supporting other students, ${ }^{[6]}$ but they also help their peers in meeting the human, psychological needs, such as love, belonging and freedom. ${ }^{[7]}$ Furthermore, by sharing common values, similar experiences and lifestyles, students feel comfortable in sharing their frustration with their fellow students. ${ }^{[8]}$ Varenhorst ${ }^{[9]}$ argued that an individual sense of uniqueness, secure membership in one's group of choice and a sense of contributing significantly to other peoples' lives are possible through peer help. Based on these premises, the peer-help programmes in higher education are foregrounded.

According to Varenhorst, ${ }^{[9]}$ the peer-help concept is an overarching term used to refer to various support services and activities that take place in different contexts. The possibilities of using peer-help programmes in many settings have produced various terms, ranging from, e.g. peer tutoring, peer helpers, peer counselling, mentors and peer leaders. ${ }^{[10]}$ Universities, community centres, organisations and schools are some of the settings with peer helpers. Despite the diversity of terms and settings, the descriptions of the peer helpers' roles are strongly connected with the types of services peer helpers are trained to offer. ${ }^{[11]}$ Most importantly, as Downe et al ${ }^{[12]}$ argued, the content of services rendered by peer helpers is of more importance than the term assigned to them.

There are conspicuous overlaps in how researchers construct peer help, and it is worth exploring how these constructions are presented through the lens of researchers. Gray and Tindall ${ }^{[8]}$ conceived peer counselling as forms of interpersonal helping behaviours undertaken by non-professional persons. For Salovey and D'Andrea ${ }^{[13]}$ active listening and problem-solving coupled with knowledge of human growth and mental health are critical features essential for peer helpers. In some instances, peer help is configured as a form of psychological education intervention, which serves to enhance the psychological and healthy functioning of individuals. ${ }^{[14,15]}$ Taking this further, Varenhorst ${ }^{[9]}$ configured peer help in a tertiary environment as encapsulating various forms of support and assisting interventions offered by trained peer counsellors in a student-to-student encounter. In summary, the rendering of helpful services to fellow peers by a trained and skilful peer helper is the central theme in the construction of peer help.

According to Simons and Cleary, ${ }^{[16]}$ students who participate in peerhelp programmes demonstrate a sense of civic responsibility and develop professional ethics by giving back to the community. At university level, peer helpers are known to play a pivotal role in motivating their fellow students to be open, and to develop and exhibit responsible attitudes and lifestyles. ${ }^{[17]}$ Gould and Lomax ${ }^{[18]}$ have strongly argued that peer helpers are capable of communicating with their fellow students in ways better than faculty and administrators. Being in a position of providing a broad range of helpful services, it cultivates a belief on the part of peer helpers that they are actively shaping their future and contributing significantly to that of other people. ${ }^{[19]}$

In some instances, the peer-help programmes are configured as the service-learning programmes within the psychology discipline and are critical for educational and personal purposes. According to Racz and Lacko, ${ }^{[20]}$ students who joined the peer-help programme usually aspire to pursue psychology as a career. For such students, peer-help programmes allow them to integrate theoretical knowledge and practical experience and create opportunities for reflection. ${ }^{[21]}$ Moreover, Simons and Cleary ${ }^{[16]}$ found that practical exposure in peer-help programmes assisted undergraduate psychology students in gaining a broader understanding of the study course and produced notable positive results on students' personal and interpersonal levels. Although there is sufficient practical exposure at postgraduate psychology level, there is little emphasis on practical learning at an undergraduate level. ${ }^{[22]}$ The dearth of practical learning in the undergraduate years could be attributed to the psychology curriculum being structured in such a manner as to open possibilities for different career paths. ${ }^{[22]}$

The peer-help programmes have well-recognised benefits, not only for the recipients of peer-help services but also for the peer helpers themselves. Odirile $^{[23]}$ stated that students' study skills and academic performance improved as a result of joining the programme. Aladağ and Tezer ${ }^{[7]}$ indicated that peer-help programmes developed students' ability to demonstrate empathy and reflective skills. Brammer and MacDonald ${ }^{[24]}$ stressed that the prestige of being selected as a peer helper brings the satisfaction of being involved in the needs of others and of contributing to another person's wellbeing. Lastly, taking part in peer-help programmes assists peer helpers in developing insights and acquiring skills such as leadership, interpersonal communication, self-knowledge and a higher level of self-esteem, and demonstrating positive personal health behaviours. ${ }^{[25,26]}$

Notwithstanding the vast spectrum of positive aspects of peer-counselling programmes, there is a marked paucity of literature on the modalities that peer helpers use to construct their roles. In a study by Marks et al. ${ }^{[27]}$ on paraprofessional experiences in inclusive education, the paraprofessionals constructed their roles as the bearers of success for the students they were assigned to help. Likewise, Patterson ${ }^{[28]}$ found that the paraprofessionals' construction of their roles reflected a sense of taking responsibility for handling the behavioural and academic issues of other students and themselves. However, there has never been a study that looked at the strategies used by UNISA peer helpers to construct their roles.

\section{Methods}

A qualitative approach was used to elicit the strategies that UNISA peer helpers used to construct their roles. The social constructionist approach that embraces the notion of multiple versions of reality and involves explaining and describing the processes people use to construct their realities, was employed as an epistemological stance. ${ }^{[29]}$ The purpose was to take peer helpers' constructions of their roles as a reflection of their 
realities. The sample consisted of 6 peer helpers who were interviewed at a time convenient to them. There were 11 peer helpers who volunteered to participate in the study. However, saturation was reached after four interviews. A further two interviews were conducted to ensure that no new information was forthcoming. All participants were undergraduate psychology students -2 males and 4 females. A semi-structured interview schedule, which focused on 4 questions, was employed to collect data. The interviews were tape-recorded, transcribed and saved in a passwordprotected sound cloud to ensure confidentiality. After the transcriptions were completed, they were returned to participants for further verification and additional information. The data were analysed using a thematic method. The purpose was to inductively identify the patterns in the data and use codes to develop patterns into themes that encapsulated participants' constructions. ${ }^{[30]}$

Ethical clearance was issued by the Department of Psychology, UNISA.

\section{Results}

The participants' constructions of their roles revealed three overarching inductive themes. The themes that emerged from the findings were organised and lodged into three broad categories: peers as distributors of information, peer-help roles as an opportunity to integrate theory and practice, and peer-help roles as a personal eye-opener. These themes are discussed individually below and are illustrated by the participants' voices.

\section{Peers as distributors of information}

The participants pointed out that the role of being a peer helper offers them the opportunity to disseminate educational information to students and the broader community. In that way, participants' constructions reveal modalities by which the distribution of information is enacted in the peerhelper role. Educational information is distributed to assist students to make informed decisions when selecting career paths, as well as when compiling a curriculum for any field of study where there are many elective modules to select from. This emerged as one of the ways in which educational information is shared. To qualify this position, one of the participants compared the role of the peer helper with that of a doctor:

'I would like to compare it to a doctor where you have people's lives in your hands. When people come in here with difficult questions regarding their careers, they are trying to find who they can talk to, where they fit in, in terms of their careers, in terms of studying, and you are that person who can actually in a way guide them.' (P4)

Constructing the peer-helper role in that way reveals the seriousness and mechanism of helping one to select a good career path. Besides, there is a sense of care and patience in how the peer helpers orientate themselves in facilitating career and decision-making processes that are done to maximise the possibilities for self-directed decision-making:

'A UNISA peer helper is more of a mentor, is more of a satellite for the community out there.' (P2)

The abovementioned extract shows the role of the peer helper as someone in service of the university student population and the broader community. Constructing the peer-helper role as a satellite implies that peer helpers are accessible and intricately connected to the needs of the current students and prospective students in communities. Furthermore, the actual interactions between peer helpers and clients - UNISA students or prospective students - are the core element of peer helping. The quote below describes a participant's feelings resulting from interactions with clients:

'It makes me feel complete and happy to hear someone appreciating what you have done, and in that way, it shows that you are playing a part at the university.' (P1)

In making sense of the peer-helper role, the abovementioned participant views the role as a means of giving back to the university, which brings satisfaction. In keeping with the theme being discussed, the participant mentioned below mapped out some of the key characteristics of what constitutes UNISA peer helpers as distributors of educational information:

'Being a peer helper is to help students in choosing careers, modules, explain the UNISA system, application, registration and what else. We help students with study skills.' (P6)

In synthesising this theme, the participants' constructions reveal the elasticity, sensitiveness and key elements underpinning UNISA peer helpers' roles and responsibilities. In so far as making a suitable career choice is concerned, the participants' constructions show the strategies peer helpers used to construct their roles as distributors of educational information and facilitators of career-decision processes.

\section{The peer-helper role as an opportunity to integrate theory and practice}

The role of the peer helper is also constructed as an opportunity to acquire practical knowledge and experience in counselling. This theme is best explained by framing it against the curriculum structure of the undergraduate psychology programme. Undergraduate psychology programmes at UNISA concentrate largely on theoretical knowledge and few practical opportunities are offered. The onus therefore rests on students to seek opportunities where they can integrate theoretical and practical knowledge. The UPHVP offers psychology students opportunities for practical experience. Based on the findings, the participants strongly emphasised that within the peer-helper role there are opportunities to apply theoretical knowledge that could not be applied outside the context of the programme. In the quote below, the participants' constructions reveal how being a peer helper enabled them to apply accumulated theoretical psychology knowledge in practice:

'To put what I have been studying into action, that is why I joined the peer help programme.' (P3)

'I thought it would help to do what I am studying practically; you know its counselling, studying psychology and doing it practically.' (P6)

Furthermore, the peer-helper role is not only constructed to offer practical opportunities in counselling, but as a role that simplifies theoretical knowledge in ways that enhance understanding and application of that knowledge. It became apparent that the peer-helper role paved ways for the integration of knowledge acquisition and its application. The opportunity to work as a peer helper also assisted the participants in making informed career decisions. Such decisions were made early in their careers as a result of helping other students; this encouraged participants to consider postgraduate programmes in psychology or to contemplate changing to other study programmes. The quotes from the participants below describe how becoming peer helpers enabled them to strike a balance between knowledge acquisition and application: 
'A lot of things are very abstract when you are studying, they are very abstract. So, one can make sense but one can make more sense if it was practical; so what I thought about this is that if I could get an environment whereby I could put into practice what I have learned, things would make more sense.' (P2)

'I wanted an environment where I can put theory into practice because I felt that yes I am studying psychology but I am not really combining or I am not really integrating. What I am learning in the book to actually practise it and see whether I can do it or not.' (P5)

Encapsulated in this theme are subjective constructions illustrating selfinitiated attempts to look for an environment that allows the integration of theoretical knowledge with practice. Furthermore, peer helpers' constructions show that they have mastered psychological literacy, which entails the ability to adapt and use psychological knowledge to satisfy personal, professional and societal needs. ${ }^{[14,31]}$ The UPHVP is configured as the site that offered practical opportunities for participants and contributed significantly to their learning and personal development.

\section{The peer-helper role as a personal eye-opener}

Lastly, this theme is constructed as a personal eye-opener because the findings show that the participants have developed a deeper level of self-insight since joining the UPHVP. The self-insight, as shared by the participants, seems to have occurred at two levels, i.e. a personal and career level. At a personal level, the participants stressed aspects related to self-knowledge in a sense that they have symbolised certain aspects of their personalities into themselves. They were not aware of these before they were helpers. Below are some of the discoveries pointed out by the participants:

'I have figured out myself, my journey, my study journey.' (P3)

'Meeting new people with different personalities on a daily basis, I also got to discover that I am not introverted as I thought I am.' (P6)

At a career level, the findings show that the participants constructed the peer-helper role as one where they were exposed to different career paths within the field of psychology. Having such exposure enabled the participants to map out their career paths with regard to postgraduate programmes:

'One thing is that I now have a clear career knowledge; there were a lot of things that I did not know before coming to this environment. So from working here I realise that I always have a clear picture of what I wanted to be, but I now have a direction to follow in order to get there.' (P5)

'It's a great experience because it helps you to discover yourself as an individual, and also to learn more about these career fields in psychology, as you know that careers evolve now and then; however, with this programme, it exposes you to things like careers research.' (P1)

For one participant the exposure obtained from being a peer helper assisted her to decide that psychology was not her field of interest:

'When I registered for the psychology qualification, I knew that I wanted to be a psychologist. I was not aware about other career options that are offered in the psychology department. So being at the peer-helper programme has helped me to decide that psychology is not my field of interest.' (P2)
In the abovementioned quote, there is a shift away in thinking about career choices. The participant was certain that the psychology programme was her field of interest; however, after the UPHVP, she started to re-evaluate her career choice. It seems that being in the UPHVP, where she was exposed to information, helped her to decide that psychology was not her field of interest.

\section{Summary of the findings}

In constructing the peer-helper role, the participants' constructions show the wealth of professional and personal benefits for them as peer helpers. Furthermore, there are tangible and intangible benefits for UNISA students and the broader community regarding information and guidance services offered by peer helpers. However, findings pose a challenge to the university to enhance the altruistic capacity inherent in students, and to consider infusing practical components in the undergraduate psychology programmes. These two elements are discussed further below.

\section{Discussion}

The participants' constructions have to a greater extent depicted the students' capacity to utilise the university resources to share valuable information with their fellow students. The students' ability to help their fellow students is not limited to UNISA, but something that is also evident in other institutions of higher education. ${ }^{[32]}$ The body of literature, along with the research conducted in this study, demonstrated that peer helpers are better equipped to assist their fellow students. ${ }^{[18,33]}$ In the current study, the participants state ways in which they expand their help services not only to their fellow students but also to reach prospective students in different communities. This shows the extent to which students are capable of contributing in shaping their future and that of other students. ${ }^{[19]}$ The sentiments shared by the participants concur with the premises guiding the formation of the UPHVP, i.e. to expand the range of counselling services to students and the broader community (Van Schoor and Mill - unpublished information, 1998). Peer helpers have similar experiences, values and lifestyles as their fellow students, ${ }^{[34]}$ which ease help-seeking behaviours and counselling relationships. One participant perceived the peer-helper role as a satellite; this indicates the extent to which peer helpers are able and open to use their skills to cultivate change in the lives of others. ${ }^{[35]}$ These sentiments tap into students' inherent resources to play a fundamental role in the lives of other students. ${ }^{[17]}$ Despite the peer helpers' contribution towards helping their fellow students, there is still a paucity of research on peer-help programmes at tertiary level. ${ }^{[7]}$ This is alarming, as the need for research-guided, peer-help programmes is critical for stable programmes and enhanced services.

Arising from this study is the need to infuse a practical component in the undergraduate psychology degrees. The role of peer help is constructed as one that offers opportunities for the acquisition of practical experience and further learning which, according to the peer helpers, ties in well with their studies. According to Racz and Lacko, ${ }^{[20]}$ joining a peer-help programme was a motivating factor for students who wanted to pursue studies in psychology. In this study, the participants actively expressed the need to integrate theoretical knowledge with practical experience. Because the undergraduate psychology programme at UNISA is theoretically saturated, the participants have been seeking an environment where the application of theoretically acquired knowledge could be implemented and tested. This opportunity for the practical implementation of knowledge 
and skills is essential in preparing students for postgraduate studies. The entrance pool at undergraduate level is large and very few students are accepted into postgraduate psychology programmes owing to limited spaces available. This leaves many students with few choices, not only regarding the application of theoretical knowledge but also opportunities for further studies. ${ }^{[22]}$ There is, therefore, a strong need to create multiple, practical opportunities for undergraduate psychology students so that they can utilise theoretical knowledge in planning their future careers if they are not accepted into postgraduate programmes. Another benefit of practical exposure is the need to reconsider one's own career options, which was impossible prior to exposure through the peer-help programme. Thus, the findings present concrete dimensions of integrated learning within the UPHVP that do not only orientate students towards their prospective career goals, but further assist them in re-evaluating their career choices. Practical exposure is configured as critical in enhancing students' understanding of the course and in developing their personal and interpersonal skills. ${ }^{[21]}$ Although it may not be an achievable intervention to infuse a substantial component of practical exposure that can accommodate all students through the peer-help programmes, the benefits of practical exposure outside the university need to be considered.

\section{Conclusion}

This article explored the strategies used by peer helpers to construct their roles at an ODL institution. The findings used by peer helpers show that the participants have an enormous capacity to assist, motivate and guide their fellow students towards the realisation of their goals. It became apparent that students have a strong understanding of the challenges faced by other students and the institutional character of the university, and that they can use their experiences in conjunction with the available resources - not only to assist their fellow students but to reach out to the community and distribute information. The second essential element observed in this study was that students who participate in university activities increase their opportunities for learning and acquiring practical knowledge. Lastly, the UPHVP has enabled peer helpers to get to know themselves and chisel their path towards self-determined career goals.

Acknowledgements. I acknowledge Johan Kruger, supervisor of my Master's degree. Author contributions. Sole author.

Funding. None.

Conflicts of interest. None.

1. Subotzky G, Prinsloo P. Turning the tide: A socio-critical model and framework for improving student success in open distance learning at the University of South Africa. Dist Educ 2011;32(2):177-193. https://doi.org/10.1080/0 1587919.2011 .584846
2. Barnard SE, Deyzel L, Lephondo MJ, et al. Adapted UNISA Peer Help Training Manual. Pretoria: University of South Africa, 2003.

3. Cole GA. Personnel and Human Resource Management. 5th ed. London: Continuum, 2002:385.

4. Myrick RD, Highland WH, Sabella RA. Peer helpers and perceived effectiveness. Element School Guidance Counseling 1995;29(4):278-288.

5. Pritchard ME, Wilson GS, Yamnitz B. What predicts adjustment among college students? A longitudinal pane study. J Am Coll Health 2007;56(1):15-22. https://doi.org/10.3200/JACH.56.1.15-22

6. Robinson SE, Morrow S, Kigin T, Lindeman M. Peer counsellors in a high school setting: Evaluation of training and impact on students. School Counselor 1991;39(1):35-40.

7. Aladağ M, Tezer E. Effects of a peer helping training program on helping skills and self-growth of peer helpers. Int J Advance Counsel 2009;31(4):255-269. https://doi.org/10.1007/s10447-009-9082-4

8. Gray HD, Tindall JA. Peer counselling. An in-depth look at training peer helpers. Accel Develop 1979;30(5):49. Gray HD, Tindall JA. Peer counselling. An in-
https://doi.org/10.1177/002248717903000523

https://doi.org/10.1177/002248717903000523
Varenhorst BB.Tapping the power of peer helping. Reclaim Child Youth 2004;13(3):130-133.

9. Varenhorst BB.Tapping the power of peer helping. Reclaim Child Youth 2004;13(3):130-133.
10. Myrick RD, Bowman RP. Becoming a Friendly Helper: A Handbook for Student Facilit

Myrick RD, Bowman RP. Becoming a Friendly Helper: A Handbook for Student Facilitators. A Leadership Training Program for Young Students. Minneapolis: Educational Media Corporation,1981.

11. Morey RE, Miller CD, Rosén LA, Fulton R. High school peer counselling: The relationship between student satisfaction and peer counsellors' style of helping. School Counselor 1993;40(4):293-300.

12. Downe AG, Altman HA, Nysevold I. Peer counselling: More on an emerging strategy. School Counsel 1986;33(5):355-364. https://www.jstor.org/stable/23901264

13. Salovey P, D'Andrea VJ. A survey of campus peer counselling activities. J Am College Health 1984;32(6):262-265. https://doi.org/10.1080/07448481.1984.9939581

14. Cranney J, Dunn DS. Psychological literacy and the psychologically literate citizen. New frontiers for a global discipline. In: Cranney J, Dunn D, eds. The Psychologically Literate Citizen: Foundations and Global Perspectives. New York: Oxford University Press, 2011:3-15.

15. Foster-Harrison ES. Peer helping in the elementary and middle grades: A developmental perspective. Element School Guidance Counselor 1995;30(2):94.

16. Simons L, Cleary B. The influence of service learning on students' personal and social development. College Teach 2006;54(4):307-319. https://doi.org/10.3200/CTCH.54.4.307-319

17. Pascarella ET, Terenzini PT. How College Affects Students: A Third Decade of Research. San Francisco: JosseyBass, 2005.

18. Gould J, Lomax A. The evolution of peer education: Where do we go from here? J Am College Health 1993;41(6):235-240. https://doi.org/10.1080/07448481.1993.9936333

19. Carter K, McNeill J. Coping with the darkness of transition: Students as the leading lights of guidance at induction to higher education. Br J Guidance Counsel 1998;26(3):399-415. https://doi.org/10.1080/03069889808253852

20. Racz J, Lacko Z. Peer helpers in Hungary: A qualitative analysis. Int J Advance Counsel 2008;30(1):1-14.

21. Roos V, Temane QM, Davis L, et al. Service learning in a community context: Learners' perceptions of a challenging training paradigm. S Afr J Psychol 2005;35(4):703-716. https://doi.org/10.1177/008124630503500406

22. Bryan J, Ranzijn R, Balfour C, et al. Increasing the work readiness of Australian psychology undergraduates through an experiential learning placement. Int J Psychol 2012;47(1):164-179. https://doi.org/00011205201201001-04467

23. Odirile L. The role of peer counselling in a university setting: The University of Botswana. Paper presented at the 20th Anniversary Summit of the African Educational Research Network at North Carolina State University Raleigh, USA, 19 May 2012 .

24. Brammer LM, MacDonald G. The Helping Relationship: Process and Skills. Boston: Allyn, Bacon, 2003.

25. Brack AB, Millard M, Shah K. Are peer educators really peers? J Am Coll Health 2008; $56(5): 566-568$. https://doi. org/10.3200/JACH.56.5.566-568

26. Good JM, Halpin G, Halpin G. A promising prospect for minority retention: Students becoming peer mentors. I Negro Educ 2000;69(4):375-383.

27. Marks SU, Schrader C, Levine M. Paraeducator experiences in inclusive settings: Helping, hovering, or holding their own? Except Child 1999;65(3):315-328. https://doi.org/10.1177/001440299906500303

8. Patterson KB. Roles and responsibilities of paraprofessionals: In their own words. Teach Except Child Plus 2006;2(5):1-13.

29. Gergen KJ. The social constructionist movement in modern psychology. Am Psych 1985;40(3):266-275. http:/ dx.doi.org/10.1037/0003-066X.40.3.266

30. Braun V, Clarke V. Using thematic analysis in psychology. Qual Resource Psychol 2006;3(2):77-101. https://doi. org/10.1191/1478088706qp063o

31. Morris S, Cranney J, Jeong JM, Mellish L. Developing psychological literacy: Student perceptions of graduate attributes. Austr J Psychol 2013;65(1):54-62. https://doi.org/10.1111/ajpy.12010

32. Naicker M, Boshoff N, Maritz G, Fourie A. The development of a comprehensive peer buddies program in a merged tertiary institution: The University of Johannesburg. J Counsel Develop High Educ South Afr 2014;1(1):12-29.

33. Burton LJ, McDonald K. Introductory psychology and psychological literacy. In: Cranney J, Dunn D, eds. The Psychologically Literate Citizen: Foundations and Global Perspectives. New York: Oxford University Press 2011:91-103.

34. Tindall, JA. Peer Programmes: An In Depth Look at Peer Helping: Planning, Implementation, and Administration. Bristol: Accelerated Development, 1995

35. Chester A, Burton LJ, Xenos S, Elgar K. Peer mentoring: Supporting successful transition for first year undergraduate psychology students. Austr J Psychol 2013;65(1):30-37. https://doi.org/10.1111/ajpy.12006

Accepted 22 January 2018 